\title{
TOXEMIA DA PRENHEZ EM PEQUENOS RUMINANTES
}

\author{
PREGNANCY TOXEMIA IN SMALL RUMINANTS \\ Maria Claudia Araripe Sucupira ${ }^{\oplus}$, Carolina Akiko Sato Cabral de Araujo $^{2}$, \\ Rodolfo José Cavalcanti Souto ${ }^{3}$, José Augusto Bastos Afonso ${ }^{3}(0$
}

\section{RESUMO}

Faculdade de Medicina Veterinária e Zootecnia (FMVZ) da Universidade de São Paulo (USP), São Paulo, São Paulo, Brasil.

Departamento de Medicina Veterinária (DMV), Universidade Federal Rural de Pernambuco (UFRP), Campus Sede, Recife, Pernambuco, Brasil.

Clínica de Bovinos de Garanhuns (CBG), Universidade Federal Rural de Pernambuco (UFRPE), Garanhuns, Pernambuco, Brasil.

Autor para correspondência: msucupir@usp.br

Revista Brasileira de Buiatria Enfermidades Metabólicas, Volume 2, Número 3, 2021

ISSN 2763-955X

DOI:10.4322/2763-955X.2021.012

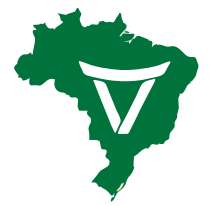

Associação Brasileira de Buiatria

\begin{abstract}
A Toxemia da Prenhez é uma enfermidade metabólica de grande relevância na ovinocaprinocultura. Na presente revisão os autores buscaram compartilhar as referências clássicas, atuais e as experiências pessoais. A doença pode comprometer desde $1 \%$ até $20 \%$ do rebanho e é de alta letalidade. Geralmente as fêmeas que desenvolvem a enfermidade têm ou baixo ou elevado escore de condição corporal e encontram-se no terço final da gestação. Os fatores predisponentes envolvem desde aqueles relacionados à gestação, quanto à nutrição; situações de estresse; e ao próprio animal, como idade e condições de saúde prévia. Embora a etiopatogenia não esteja completamente elucidada, está relacionada à falha adaptativa ao balanço energético negativo, este último, frequente ao final da gestação. As manifestações clínicas normalmente incluem sinais nervosos, digestivos e, nos exames laboratoriais, pode-se encontrar hipo, normo ou hiperglicemia; cetose; e acidose metabólica. Com o progredir da doença, há agravamento do quadro clínico, com maior comprometimento metabólico e piora do prognóstico. $\mathrm{O}$ diagnóstico padrão-ouro é estabelecido pela determinação sérica/plasmática de beta-hidroxibutirato, outras possibilidades são apresentadas. $\mathrm{O}$ tratamento deve ser instituído o mais breve possível, proporcionando aumento na disponibilidade de glicose ao animal tanto de forma direta quanto por meio de seus precursores, bem como na correção de outros desequilíbrios, quando presentes. Conclui-se que devido à relativa baixa taxa de sucesso, mesmo com implementação precoce do tratamento, as medidas de prevenção da Toxemia da Prenhez são imperativas e estão relacionadas aos cuidados com a alimentação de acordo com as exigências em relação à energia e proteína; agrupamento das fêmeas quanto ao o número de fetos, para facilitar o manejo alimentar; controle do escore de condição corporal, evitando extremos; redução das situações de estresse, principalmente no terço final da gestação, controlando enfermidades, evitando manipulação, transporte, super lotação, dentre outras.
\end{abstract}

Palavras-chave: fetos múltiplos, gestação, metabolismo energético, metabolismo de lipídeos.

\section{ABSTRACT}

Pregnancy Toxemia is a major metabolic disease in sheep and goat farming. In this review, the authors described classic and current references and personal experiences. The disease can affect from 1 to $20 \%$ of the herd and it is high lethality. Generally, females that develop the disease have a low or high body condition score and are in the final third of the pregnancy. Predisposing factors range from those related to pregnancy; regarding nutrition; to stressful situations and to the animal itself, such as age and previous health conditions. Although the etiopathogenesis is not completely elucidated, it is related to adaptive failure to negative energy balance, which is frequent in late pregnancy. Clinical signs usually include nervous and digestive manifestations and, in laboratory tests, hypo, normo or hyperglycemia can be found; and ketosis and metabolic acidosis are present. With the progress of the disease the clinical signs worsen, with greater metabolic impairment and a worsening in the prognosis. The gold standard to the diagnosis is serum/plasma determination of beta-hydroxybutyrate, although other possibilities are presented. The treatment must be instituted as soon as possible, providing an increase in the availability of glucose to the animal, both directly and through its precursors as well as in the correction of other imbalances, when present. It is concluded that, due to the relatively low success in the therapy, even with early implementation of the treatment, measures to prevent Pregnancy Toxemia are essential and are related to care with food according to the requirements in relation to energy and protein; grouping of females according to the number of fetuses, to facilitate feeding management; control of the body condition score, avoiding extremes; reduction of stressful situations, especially in the final third of pregnancy, controlling illnesses, avoiding handling, transport, overcrowding, among others. 


\section{INTRODUÇÃO}

A gestação das ovelhas e das cabras tem duração média de $150( \pm 5)$ dias e é um período de grande relevância para o sistema produtivo. Nessa fase deve-se atentar para uma série de cuidados especiais com o intuito de reduzir perdas como mortalidade embrionária, má formação fetal, abortamentos e doenças. Dentre as enfermidades não infecciosas que ocorrem nessa ocasião, a Toxemia da Prenhez (TP) merece destaque, não só pelo comprometimento da saúde, mas também pelo grande prejuízo econômico por ela causado, especialmente por ser mais frequente nos animais criados em sistemas intensivos, resultando na maior parte dos casos, na perda da ovelha/cabra e dos cordeiros/cabritos e, portanto, de material genético de elevado valor ${ }^{1,2}$.

A TP é uma doença metabólica que ocorre no terço final da gestação, principalmente nas últimas três a duas semanas do parto, é deflagrada pela disfunção dos metabolismos de carboidratos e lipídios, decorrentes do balanço energético negativo em consequência do aumento da exigência de glicose para o crescimento fetal. É de alta letalidade e acomete principalmente ovelhas e cabras super ou subalimentadas, gestantes de dois ou mais fetos e que normalmente apresentam hipoglicemia, cetose, acidose metabólica, sinais nervosos e digestivos que culminam, frequentemente, com a morte do animal ${ }^{3-9}$.

Alguns dos sinônimos utilizados para a TP são "toxemia da gestação", "doença da gestação", "doença dos (cordeiros ou cabritos) gêmeos", "cetose gestacional", "cetose do parto", "paralisia do parto (do cordeiro/cabrito)", "acetonemia gestacional" e até mesmo "síndrome do fígado gordo (na ovelha/cabra)",6,9.

No conhecimento dos autores, o primeiro relato da doença é de 1854, feito por Seaman, na Inglaterra. Em 1924, John M'Fadyean, escocês, veterinário e professor no Royal Veterinary College, alertou para o aumento da frequência da enfermidade, descrevendo casos clínicos em ovelhas da Grã-Bretanha. No Brasil, o primeiro relato da enfermidade ocorreu em 1989 pelos professores Ortolani e Benesi, que descreveram casos em cabras e ovelhas no estado de São Paulo.

A TP pode ser do tipo $1 \mathrm{e}$ do tipo $2^{10}$. A do tipo 1 é caracterizada por processo mais crônico, acomete fêmeas com baixo escore de condição corporal (ECC), isto é, menor ou igual a 2 , na escala de 1 a 5 , e ocorre por aporte insuficiente de energia no decorrer da gestação, em especial, no seu terço final, levando à manifestação da hipoglicemia, mais frequentemente, no último mês de gestação.

Já a TP do tipo 2, ocorre nas fêmeas com elevado ECC, normalmente maior que 3,5, consequência do excesso de energia na dieta consumida durante toda a gestação, fazendo com que a fêmea chegue, no terço final, com sobrepeso ou obesa. Assim, na TP tipo 2, a hipoglicemia ocorrerá de forma súbita e todo o processo é mais agudo.

Outra forma de classificação da TP seria quanto a sua origem, isto é a TP pode ser primária ou secundária a outra enfermidade. Na TP primária, não há aporte suficiente de nutrientes para suprir o aumento da exigência energética do final da gestação e na secundária, a TP é consequência de outra condição e/ou enfermidade que aumenta ainda mais a exigência energética deflagrando o quadro 9 .

Embora não haja dados formais quanto a epidemiologia da TP, com base na descrição de relatos de caso, sabe-se que ocorre em todo mundo, e que tem relação importante com o alimento e o manejo alimentar. Nesse sentido, rebanhos bem manejados podem apresentar casos esporádicos, com baixa morbidade, isto é, menos que $3 \%$, geralmente entre $1 \%$ e $2 \%$, das fêmeas manifestando a doença ${ }^{6}$. Porém a TP pode ocorrer na forma de surtos, comprometendo até $20 \%$ ou mais das fêmeas gestantes do rebanho e, independentemente da forma como aparece, a letalidade da TP é maior que $80 \% \%^{6,11}$. 


\section{FATORES PREDISPONENTES}

Os fatores predisponentes dessa enfermidade estão relacionados à gestação, nutrição, estresse e ao animal.

- Gestação: apesar das fêmeas gestantes de apenas um feto, poderem desenvolver $\mathrm{TP}^{11}$, fêmeas com gestação de dois ou mais fetos têm maior predisposição à enfermidade ${ }^{3,8,12}$. Dessa forma, assume-se que raças prolíficas que tendem a ter maior número de fetos por gestação, são também as mais predispostas.

- Nutrição: no final da gestação o feto desenvolve-se rapidamente e adquire cerca de $75 \%$ a $80 \%$ do peso que chegará ao nascimento, dessa forma, é necessário que esse aumento na exigência de nutrientes para o crescimento fetal e início da produção de leite sejam supridos, via dieta ${ }^{13}$.

Animais com ECC igual ou menor que 2 (escala de 1 a 5) e igual ou maior que 4, são mais predispostos à $\mathrm{TP}^{8,12}$.

Portanto, nas situações de baixo ECC, são fatores predisponentes tanto a quantidade insuficiente ou a ausência de nutriente(s) quanto a baixa qualidade da dieta, isto é, alimentos mal-conservado e/ou dietas desbalanceadas ${ }^{6,14-16}$.

No caso de ECC elevado, o excesso de alimento no início e/ou durante a gestação predispõe o animal à TP, pois pode levar ao acúmulo de gordura que, predispõe a fêmea ao menor consumo de matéria seca, maior mobilização de reservas e maior redução no consumo de alimentos ${ }^{16,17}$.

- Estresse: situações estressantes podem predispor ao desenvolvimento da TP, pois levam ao aumento do gasto energético e à redução no consumo de matéria seca. São exemplos dessas situações, as condições climáticas adversas (seca excessiva, calor úmido, vento, chuva intensa); transporte prolongado; elevada densidade de animais no galpão/pasto, levando à competição por alimento; grandes áreas para pastagem com pasto de baixa qualidade ou escasso; medidas de mane- jo como tosquia, vacinação, apara de cascos, vermifugação etc. Nessas situações, ocorre elevação dos teores de cortisol, fato frequentemente encontrado em ovelhas e cabras com $\mathrm{TP}^{2,14,16-18}$.

- Animal: alguns fatores, ainda não completamente identificados, tornam certos indivíduos mais susceptíveis que outros, na chamada "susceptibilidade individual" que parece estar relacionada à eficiência do metabolismo hepático e à habilidade em manter concentrações responsivas de insulina por parte da fêmea gestante 9

Ainda relacionado ao animal, porém ganhando mais importância nas últimas décadas, a resistência insulínica tem sido considerada como fator predisponente para a ocorrência da $\mathrm{TP}^{19}$.

Fêmeas estabuladas, com restrição de movimentação, isto é, impossibilitados de se exercitarem são mais predispostas à $\mathrm{TP}^{14,16}$.

Animais com menor número de dentes incisivos ou com eles desgastados; velhos; predispostos a verminoses e a ectoparasitas; acometidos por outras enfermidades, como pneumonia, mastite, pododermatites ou outras que levam ao menor consumo de matéria seca e/ou aumento do metabolismo e à maior exigência nutricional, são considerados predispostos à $\mathrm{TP}^{6,9,16}$.

\section{PATOGENIA}

Embora considere-se que a ruptura da homeostase da glicose seja o gatilho para a TP e alguns estudos tenham sido conduzidos para esclarecer os mecanismos moleculares da doença, sua patogenia ainda não está totalmente elucidada ${ }^{6,20,21}$.

No terço final da gestação, de 30\% a 40\% da glicose produzida é direcionada para a unidade fetoplacentária, e nesta fase o(s) feto(s) desenvolve(m) até $80 \%$ do peso ao nascimento, o que aumenta a exigência nutricional da fêmea que, por dispor de menor espaço ruminal, reduz o consumo de matéria seca e entra em balanço energético negativo ${ }^{6,22}$. 
O balanço energético negativo (BEN) leva a mobilização de reservas para manter a homeostase e então, inicialmente são utilizadas a pequena reserva de glicogênio hepático e, na sequência, ocorre a mobilização dos tecidos muscular e adiposo, em resposta considerada adaptativa e fisiológica ${ }^{23,24}$.

A mobilização das reservas lipídicas inicia, quando as concentrações de insulina declinam em relação às concentrações de glucagon. Nesses períodos de $\mathrm{BEN}$, as concentrações de glicose podem diminuir ligeiramente e a relação insulina:glucagon declina fazendo com que outros hormônios como, catecolaminas e hormônio de crescimento, ativem a lipase hormônio sensível (LHS) mobilizando triglicerídeos do tecido adiposo em ácidos graxos não esterificados (AGNEs) e glicerol ${ }^{19,24}$.

Os AGNEs são transportados pela albumina até o fígado, onde poderão ser oxidados ou reesterifica- dos. Para serem oxidados, os AGNEs devem entrar na mitocôndria e, essa passagem é dependente da ação da enzima carnitina-aciltransferase $\mathrm{I}^{25}$. Na mitocôndria, a oxidação pode ocorrer por duas vias, a completa ( oxidação), quando há oxaloacetato, nas situações фe aporte adequado de carboidratos ou seus precursores; e a incompleta, também considerada fisiológica, e que levará à síntese de corpos cetônicos ${ }^{25-27}$ (Figura 1).

Os corpos cetônicos produzidos se difundem livremente no sangue e são utilizados como suprimento energético em diversos tecidos ${ }^{3,6,15}$. A acetona é volátil, e o oxaloacetoacetato é instável, dessa forma o betahidroxibutirato (BHB) é o corpo cetônico mais estável no organismo e, portanto, o principal corpo cetônico encontrado em casos de cetose ${ }^{28}$.

Em síntese, no terço final da gestação, as ovelhas e cabras, entram em BEN, e, para obter energia, mobilizam tecido adiposo aumentando os teores circu-

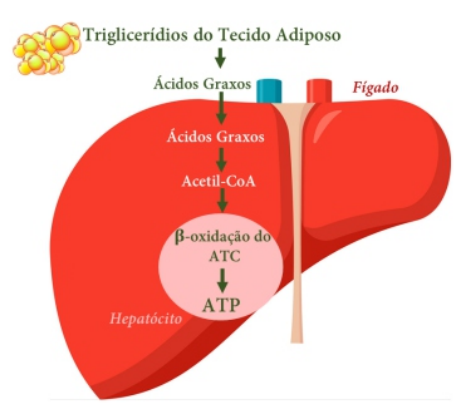

A

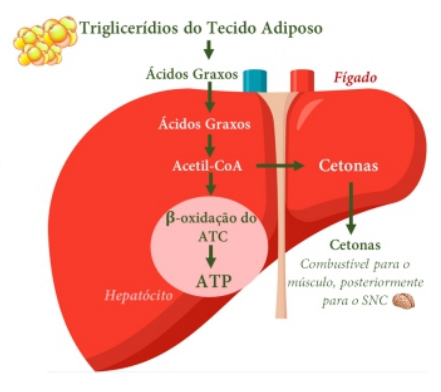

B

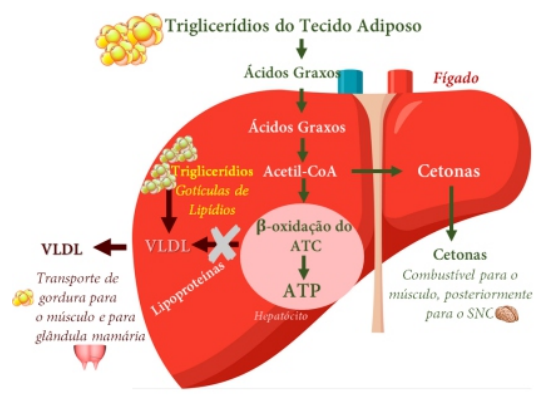

(C)

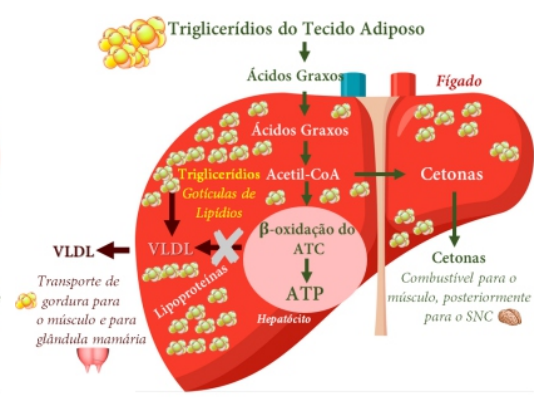

D

Figura 1. Esquema do metabolismo de lipídios em situação fisiológica (A e B) e de esteatose hepática (C e D). (A) Durante a fase pós absortiva do metabolismo, o tecido adiposo libera ácidos graxos não esterificados no sangue, onde circula a albumina. Os hepatócitos capturam esses ácidos graxos, que são degradados em unidades de dois carbonos e combinados com coenzima A para formar acetil-CoA, que é oxidada por meio do ciclo do ATC cadeia de transporte de elétrons mitocondrial a $\mathrm{CO}_{2}$, gerando ATP. (B) A capacidade dos ácidos graxos de sofre beta-oxidação completa é limitada, e parte da acetil CoA é então convertida em beta-hidroxibutirato e acetoacetato para exportação até outros tecidos capazes de utilizá-los como fonte de energia.(C) A medida que se aproxima o limite de produção de cetonas os hepatócitos começam a converter os ácidos graxos livres em triglicerídios. Em seguida, os triglicerídios são envolvidos em lipoproteínas para formar partículas conhecidas como lipoproteínas de densidade muito baixa (VLDL) para transporte fora dos hepatócitos e exportação para outras células. (D) Em algumas espécies, a capacidade de produzir VLDL é limitada, e ocorre acúmulo de triglicerídios no interior das células até alcançar níveis patológicos que comprometem a função dos hepatócitos, uma condição conhecida como esteatose hepática ${ }^{28}$. 
lantes de AGNEs. As fêmeas que desenvolvem TP, por uma falha na resposta adaptativa a essa situação, metabolizam os AGNEs, em grandes proporções, de forma incompleta a corpos cetônicos e os que não conseguem entrar na mitocôndria para essa oxidação incompleta, são reesterificados e acumulados, como triglicerídeos, nos hepatócitos, levando à esteatose hepática, comprometendo, ainda mais a função hepática celular e a produção de glicose $e^{9,23,29}$. Ressalta-se que, os AGNEs reesterificados a triacilgliceróis em condições fisiológicas, são transportados do fígado via lipoproteínas $(\mathrm{VLDL})^{25,30}$, entretanto, como os ruminantes possuem limitada capacidade de sintetizar VLDL, em condições de TP, passa a haver acúmulo de triglicerídeos no fígado nas situações de elevadas concentrações de AGNEs no sangue ${ }^{29}$.

Considera-se que a habilidade em manter as concentrações de insulina funcionais e a resposta a essas no tecido materno tenham papel chave nas adaptações metabólicas ao BEN, pois, apesar de nessa situação as concentrações de insulina normalmente estarem reduzidas, tem-se observado que a TP também está relacionada à insuficiência na utilização da glicose e não apenas à sua produção, o que chama a atenção para a relação dos casos de resistência insulínica como fator predisponente para a doença $a^{6,19,31,32}$. Diante desse cenário, na evolução da TP, não há padrão nas concentrações de glicose, podendo o animal apresentar tanto hipoglicemia como normo ou hiperglicemia.

Outro hormônio possivelmente envolvido na patogenia da TP é o cortisol. Constatou-se aumento dos teores desse hormônio em $80 \%$ das ovelhas acometidas por TP tanto na forma clínica como na forma inaparente, provavelmente ou por aumento da atividade das adrenais, ou decorrente da hipoglicemia, ou devido à menor metabolização hepática ou ainda devido a presença de fatores estressantes, como também a morte fetal $^{2,5,12,20,33-36}$.

Tanto na TP aparente como na inaparente, sugere-se o comprometimento da resposta imune celu- lar e humoral, pois foram observadas redução na IgG antígeno específica com o aumento dos AGNEs plasmático ${ }^{1}$. $\mathrm{O}$ envolvimento do metabolismo oxidativo também tem sido considerado na patogenia da TP, credita-se ao acetoacetato o aumento da geração de radicais superóxido elevando o estresse oxidativo e, portanto, maior peroxidação lipídica, alterando a permeabilidade de membranas, organização de lipídios e até mesmo a morte celular ${ }^{37}$.

\section{MANIFESTAÇÕES CLÍNICAS DA TP}

As manifestações clínicas nas fêmeas que desenvolvem a TP podem variar. Essa variação está condicionada à evolução dos processos metabólicos e à severidade da doença ${ }^{9}$. De maneira geral, o quadro clínico evolui entre dez e vinte dias para animais com subnutrição (TP tipo 1) e de três a nove dias para fêmeas com boa condição corporal (TP tipo 2), ou obesas ${ }^{38}$.

Os primeiros sinais clínicos da TP geralmente são vagos e quase imperceptíveis. As fêmeas afetadas passam a se isolar do rebanho, não conseguem acompanhar o grupo no pastoreio ou não se levantam como os outros animais do lote para se alimentarem e mesmo junto do rebanho, no local de alimentação, não consomem alimento ${ }^{39}$.

À medida que as condições de hipoglicemia e o excesso de corpos cetônicos evoluem no organismo, os sinais tornam-se mais evidentes e se agravam. Os animais se isolam dos demais indivíduos do rebanho, apresentam diminuição da consciência, muitas vezes ficam apáticos, há sinais de cegueira, vagam sem rumo e, por vezes, assumem a posição de "mirar estrelas" ou ainda, permanecem parados no mesmo local aparentemente sem “objetivo" e podem apresentar até mesmo relutância para se movimentarem ${ }^{6,39}$ (Figura 2A).

A hiporexia se acentua com o progresso da enfermidade, agravando mais o quadro. Surgem atonia ruminal, aumento de frequência cardíaca, taquipneia e 
dispneia. A pulsação e os movimentos respiratórios aumentam à medida que se desenvolve a acidose metabólica e/ou choque séptico, este último decorrente da autólise dos fetos ou quadro infeccioso concomitante à $\mathrm{TP}^{39,40}$. A temperatura retal geralmente se mantém dentro dos limites de normalidade ${ }^{39}$. Em cabras, podese observar fezes mais escassas e fluidas bem como edema de membros ${ }^{35,41}$.

Nas fases mais avançadas da doença é comum a constipação, ranger de dentes, vocalização e o apareci- mento de outros sinais neurológicos como incoordenação, tremores musculares, mímica da mastigação, salivação excessiva, pressionar a cabeça contra uma superfície ou objetos e movimentos de "se lamber" (Figura 2B). Em estágios finais pode-se observar convulsões, depressão profunda e coma, seguidos da morte do animal (Figuras $2 \mathrm{C} \mathrm{e} \mathrm{D).}$

Essa evolução das manifestações clínicas pode ser agrupada em três fases distintas ${ }^{38}$.
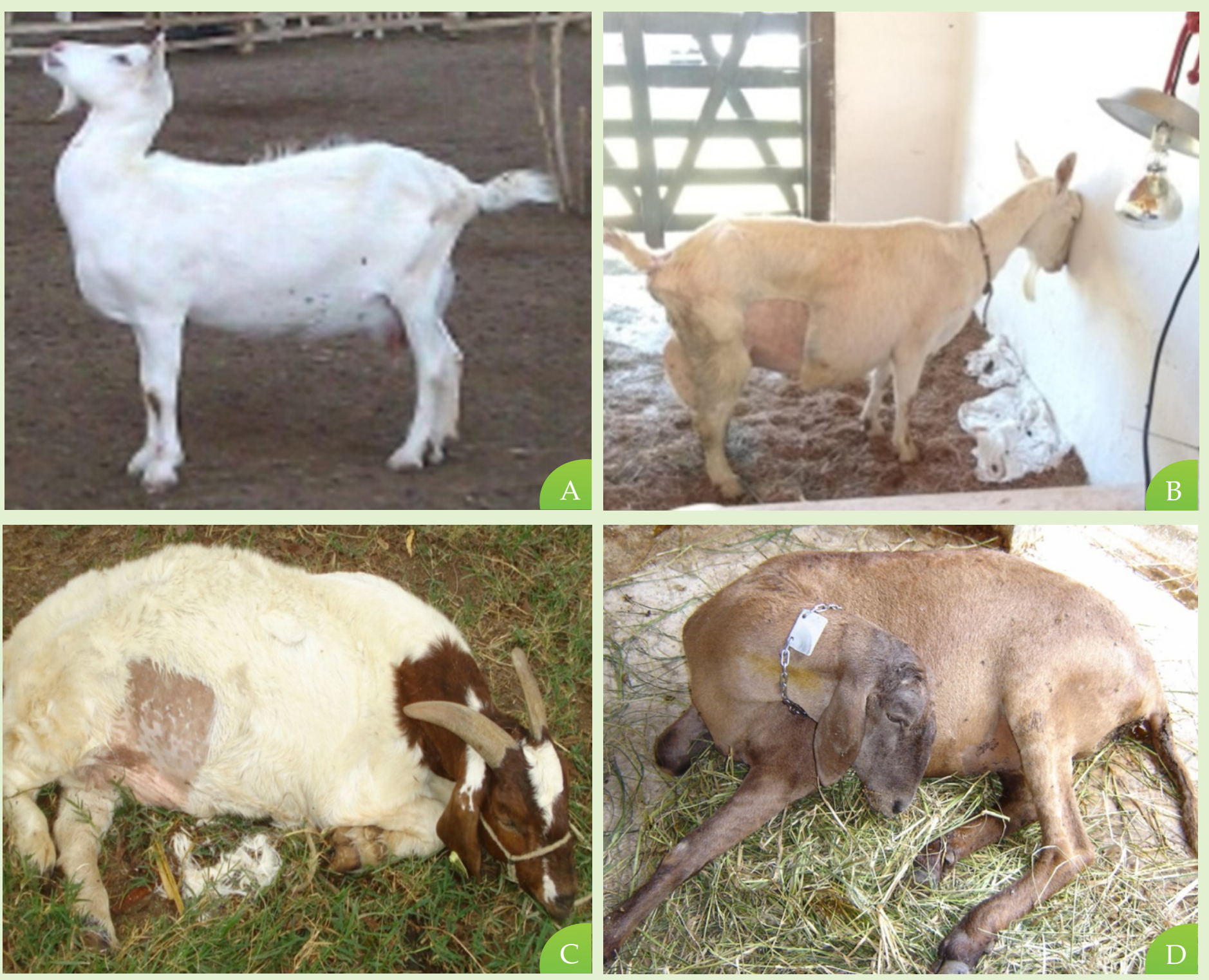

Figura 2. Sinais clínicos de Toxemia da Prenhez. (A) Cabra Saanen com manifestação de "mirar estrelas", bastante característico na progressão da doença, (B) cabra Saanen pressionando a cabeça contra a parede (head pressing), (C) cabra Boer apresentando prostração e relutância a se movimentar e (D) ovelha Santa Inês em estágio final da doença com depressão profunda (Fonte: Clínica de Bovinos de Garanhuns, UFRPE). 


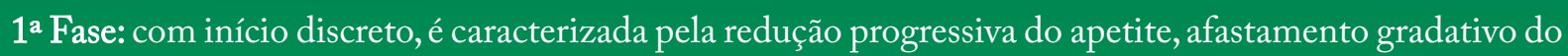
animal do restante do rebanho e início dos primeiros sinais nervosos, como diminuição da consciência, apatia, andar sem objetivo e pressão da cabeça em obstáculos.

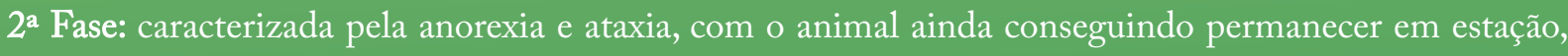
porém com um pouco de dificuldade e, dessa forma, pode ficar com os membros abertos para aumentar a base de apoio; às vezes até ficando na postura de cão sentado; tem olhar vago, fica indiferente ao ambiente, pode apresentar a surdez e/ou cegueira cortical; pode haver pequeno aumento nas frequências cardíaca e respiratória e diminuição dos movimentos ruminais; a temperatura fica dentro dos valores fisiológicos normais; pode apresentar mímica de mastigação, ranger de dentes, constipação, andar sem objetivo e pressão da cabeça em obstáculos.

3a Fase: o animal fica impossibilitado de se levantar e permanece em decúbito inicialmente esternal que evolui para o lateral; há aprofundamento da diminuição da consciência; flacidez da musculatura abdominal; aumento das frequências cardíaca e respiratória; pela desidratação, pode haver menor perfusão renal, levando à uremia e oligúria; convulsões e coma que normalmente antecedem a morte ${ }^{38}$. Como o cérebro dos ruminantes não usa os corpos cetônicos como fonte de energia, as alterações no sistema nervoso central são atribuídas à hipoglicemia que pode levar à necrose neuronal e encefalopatia ${ }^{10204}$

A hipercetonemia também pode ter papel no quadro nervoso da TP, principalmente devido ao aumento dos teores de isopropil álcool, que é metabolizado em hidroxibutirato e acetona, porém esse fato só foi confirmado em $\operatorname{vacas}^{20,43}$. As alterações nervosas ocorrem de acordo com a área cerebral afetada que é comprometida e está relacionada com a demanda pela glicose. Portanto, o primeiro local a ser comprometido é o córtex cerebral, responsável pelas manifestações clínicas de diminuição da consciência, menor resposta ou ausência de reação aos estímulos externos/ambiente, surdez/cegueira cortical; hiporexia ou anorexia; na sequência, há comprometimento cerebelar, aparecendo os sinais de ataxia e postura, bem como movimentos de rotação; na fase final, com o diencéfalo acometido, observa-se a mímica de mastigação e ranger de dentes ${ }^{10}$.
Alguns animais podem apresentar sinais de melhora quando há morte fetal, momento em que ocorre pico glicêmico e há glicose disponível. Porém, a autólise fetal subsequente pode predispor o animal a alterações sistêmicas e reprodutivas e, não raro, à morte. A cetoacidose que se instala em alguns indivíduos nos quadros de TP exercem impacto negativo, levando tanto a partos distócicos como comprometendo a taxa de sobrevida neonatal, sendo que os fetos que sobrevivem, frequentemente nascem pequenos e fracos ${ }^{15,16,39,44}$.

\section{DIAGNÓSTICO}

O diagnóstico da TP pode ser simples, quando são disponíveis informações do histórico do rebanho e há possibilidade de se realizar a anamnese, exame físico, exames complementares e/ou necrópsia e análise dos 
resultados das lesões post mortem ${ }^{45}$.

Quando o diagnóstico é feito somente por meio do exame físico, observando-se as manifestações clínicas, considera-se que normalmente os animais acometidos são as fêmeas no terço final de gestação, principalmente nos últimos vinte dias que antecedem o parto. O período de lactação, principalmente em cabras leiteiras, também deve ser considerado, mesmo com as manifestações clínicas menos intensas, pois são importantes para o diagnóstico de cetose.

Como os sinais clínicos são comuns a outras enfermidades, deve-se fazer o diagnóstico diferencial com hipocalcemia, raiva, polioencefalomalácia, listeriose, abscesso cerebral, acidose e hipomagnesemia ${ }^{15,16,46}$. A hipocalcemia pode ocorrer concomitantemente ao quadro de TP e pode ser diferenciada da mesma por ter aparecimento súbito; evidente miastenia; evolução em curto espaço de tempo, isto é, em período de 12 a 24 horas; e os animais respondem muito bem ao tratamento com soluções de sais cálcio, pela via intraveno$\mathrm{sa}^{16}$.

Entretanto, a confirmação do diagnóstico de TP necessita de exames complementares ${ }^{15,34}$. O teste padrão-ouro para hipercetonemia é a determinação da concentração plasmática ou sérica de BHB, que é mais estável após a coleta do que as concentrações plasmáticas/séricas de acetona ou acetoacetato ${ }^{16}$. Considera-se que as cabras e ovelhas com teores de BHB:

• < 0,8 mmol/L estão saudáveis.

- Entre 0,8 a 1,6 mmol/L estão com TP inaparente.

• >1,6 mmol/L estão com alguma manifestação clínica da TP (animais com subnutrição severa)

- > 3,0 mmol/L com manifestações clínicas evidentes $^{15,33}$ (Figura 3).

Apesar do padrão ouro ser a determinação laboratorial dos teores séricos ou plasmáticos de $\mathrm{BHB}$, tem aumentado o uso de aparelhos portáteis humano e veterinário para a determinação de $\mathrm{BHB}$ e glicose em ovelhas e cabras, facilitando em relação a custo e tempo de obtenção do resultado ${ }^{47,48,50,51}$. Ressalta-se que o aparelho a ser utilizado deve ter sido validado por pesquisa científica, pois, em alguns casos, não há correlação tão adequada do teste portátil com o padrão ouro ${ }^{48}$.

Os teores de $\mathrm{BHB}$ podem ser determinados também no líquor e no humor vítreo, com teores superiores a $5,0 \mathrm{mmol} / \mathrm{L}$ e $2,5 \mathrm{mmol} / \mathrm{L}$, respectivamente nos animais com $\mathrm{TP}^{16}$.

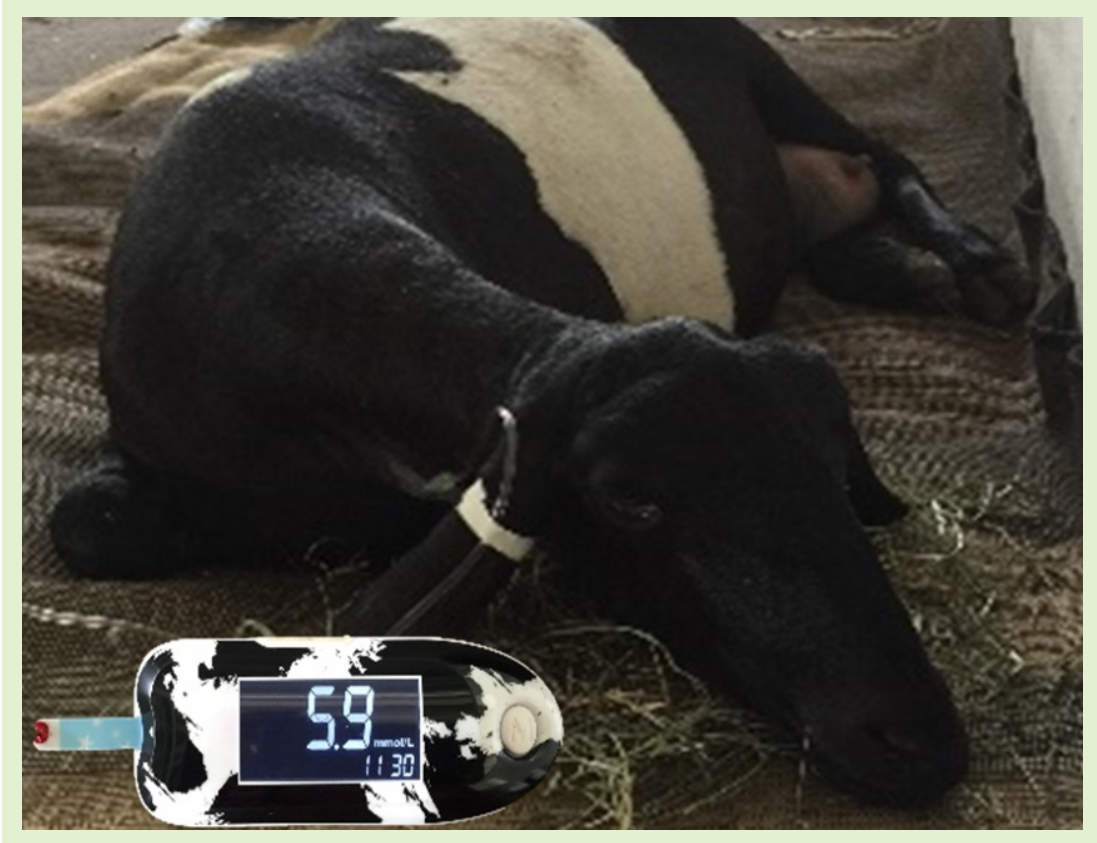

Figura 3. Ovelhas da raça Santa Inês acometida pela Toxemia da Prenhez, prostrada, após parição de dois fetos, apresentando hipercetonemia $(5,9$ mmol/L) diagnosticada após mensuração de ßhidroxibutirato utilizando gota de sangue e aparelho portátil Ketovet ${ }^{\circledR}$ (KetoVet Brasil, TaiDoc Technology, Taiwan, China) (Fonte: Ambulatório de Grandes Animais DMV Campus Recife). 
Outra possibilidade seria por meio do uso de fitas reagentes para detectar corpos cetônicos na urina por meio do nitroprussiato de sódio, que é um método rápido e relativamente específico, realizado "ao pé do animal" e cujos resultados, complementados com o exame físico, levam ao diagnóstico confiável $1^{52-54}$ (Figura 4).

A determinação da glicemia, do $\mathrm{pH}$ urinário e principalmente do $\mathrm{pH}$ sanguíneo, com os eletrólitos e a função hepática e renal, apesar de não serem fundamentais para o diagnóstico, representam importante ferramenta para instituição do protocolo de tratamento e para estabelecer o estágio de progresso da TP. A hipoglicemia normalmente está presente nos estágios iniciais e, quando o animal fica em decúbito, isto é, com o agravamento do quadro clínico, a glicemia pode estar normal ou até mesmo elevada ${ }^{16}$. A acidose metabólica aumenta progressivamente e pode ser importante com o evoluir do quadro. Pode ocorrer falência renal com manifestação de uremia e desidratação. As enzimas hepáticas, aspartato aminotransferase (AST) e gama glutamil transferase (GGT) estão aumentadas, bem como a creatina quinase $(\mathrm{CK}) \mathrm{e}$, como os teores de cortisol séricos ${ }^{2,16,18,36}$.

Os achados de necropsia devem ser considerados e são importantes no diagnóstico da TP. Os animais podem estar desidratados e o útero apresenta, na maior parte das vezes, mais de um feto. A carcaça está usualmente emaciada ou em boa condição corporal com grandes quantidades de gordura abdominal, principalmente no omento maior e mesentério, e com gordura subcutânea(Figura 5).

O fígado frequentemente está aumentado, pálido e friável, com importante degeneração gordurosa. Ele varia na cor de rosa pálido ao laranja amarelado, é muitas vezes gorduroso ao toque e, em alguns casos, irá flutuar em água ${ }^{15,39}$ (Figura 6).

Os rins macroscopicamente não apresentam alterações marcantes, notando-se palidez de sua superfície em alguns animais magros e leve coloração amarelada em animais gordos ${ }^{34}$. As lesões histológicas caracterizam-se por lipidose hepática e acentuada degenera-
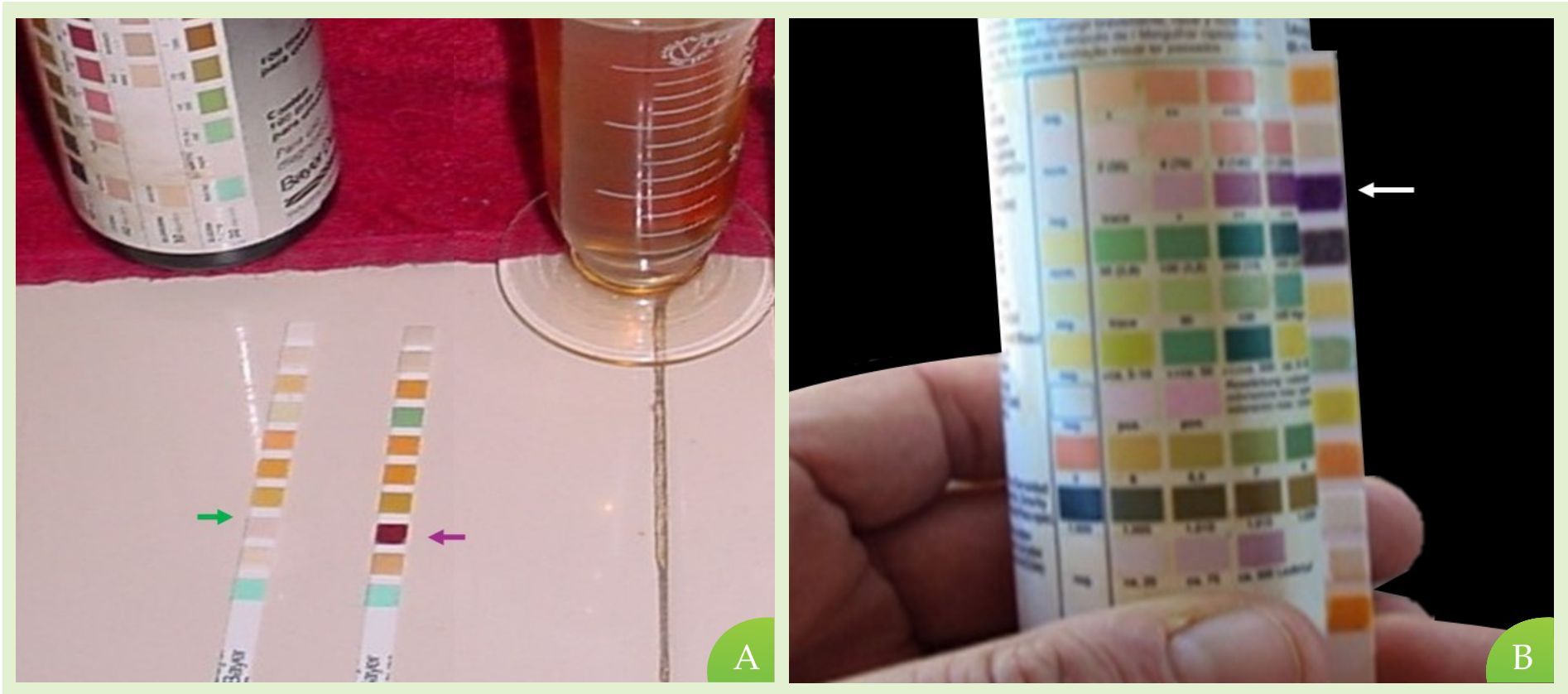

Figura 4. Deteç̧ão de corpos cetônicos na urina por meio do nitroprussiato de sódio em fita reativa. (A) Determinação de corpos cetônicos por meio de fitas reativas em animais saudável (seta verde) e afetado por Toxemia da Prenhez (seta roxa) e (B) teste positivo (seta branca) para dosagem de corpos cetônicos por meio de fitas reativas (Fonte: Clínica de Bovinos de Garanhuns,UFRPE). 

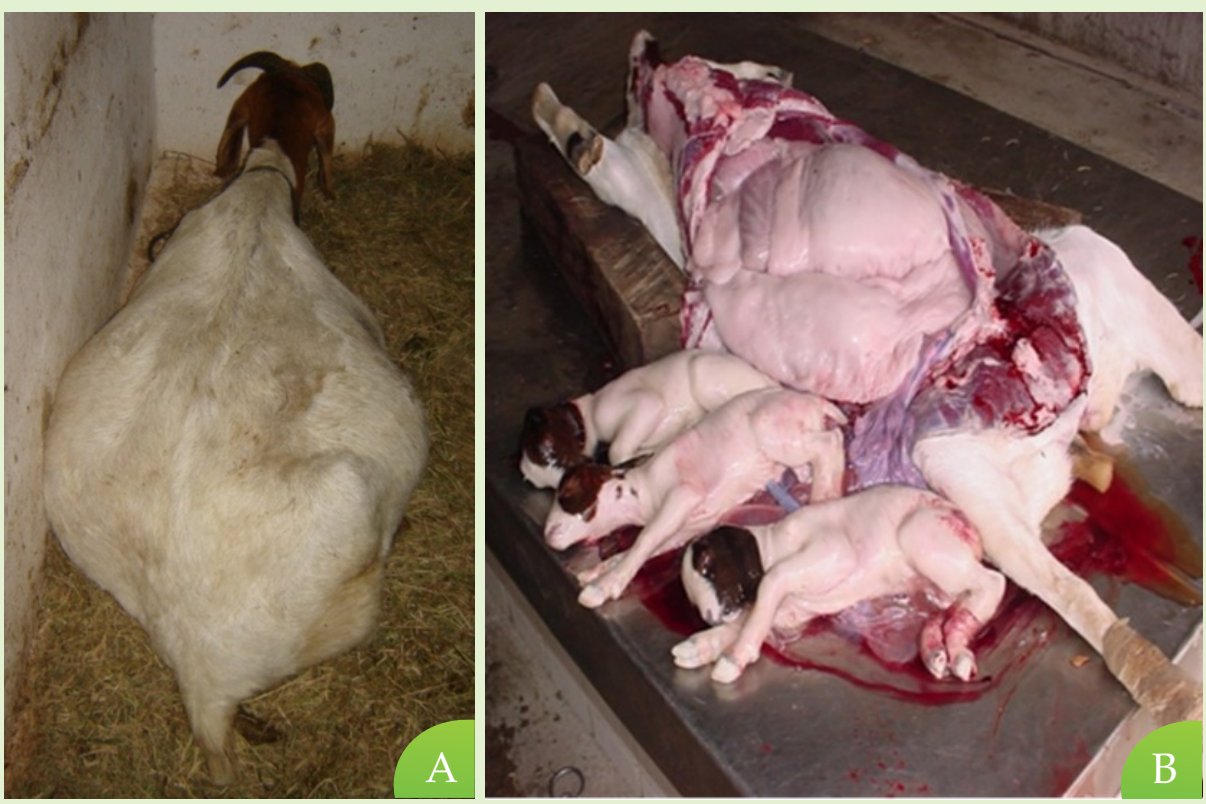

Figura 5. (A) Cabra da raça Boer com Toxemia da Prenhez (3a Fase) e (B) e sua necropsia onde é constatada a presença de múltiplos fetos (Fonte: Clínica de Bovinos de Garanhuns, UFRPE).
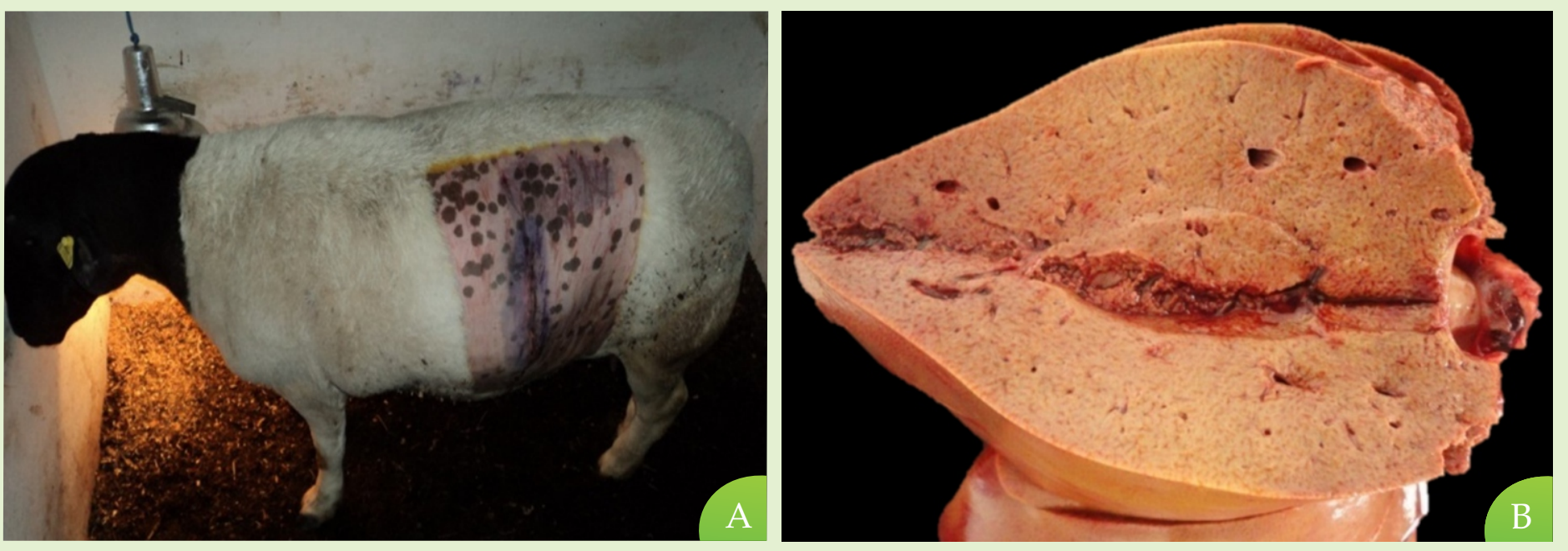

Figura 6. (A) Ovelha da raça Dorper com Toxemia da Prenhez e (B) correspondente imagem de fígado seccionado apresentando esteatose constatada à necropsia do animal (Fonte: Clínica de Bovinos de Garanhuns, UFRPE).

ção gordurosa dos hepatócitos ${ }^{34,55}$. Nos rins, podem ser encontradas acentuadas vacuolizações em células epiteliais tubulares ${ }^{34}$. Evidências de degeneração e necrose neuronal do tipo isquêmica no córtex cerebral de ovelhas com TP foram descritas provavelmente em função de encefalopatia hipoglicêmica ${ }^{16,42}$. Em recente trabalho, Zainal Ulum et al. ${ }^{56}$ constataram que a TP em cabras produz lesões nos órgãos reprodutivos de fêmeas e no fígado de fetos, afirmando que as lesões de hipomaturidade e necrose de vilosidades coriônicas, glândulas endometriais uterinas e necrose hepática fetal desempenham papéis importantes em relação à morte fetal intrauterina e de natimortos.

\section{PROGNÓSTICO}

O prognóstico para a TP é difícil de ser estabelecido, porém, de maneira geral, é de reservado a mau e tende a ficar mais para mau quando os fetos estão mortos e a fêmea tem sinais de fraqueza muscular permanecendo em decúbito. Também é considerado desfavorável com a evolução da enfermidade, pois, a acidose metabólica, o desbalanço eletrolítico, a desidratação e o comprometimento renal tendem a evoluir, dificultando progressivamente a reversão do quadro ${ }^{57}$. 
Alguns autores têm associado variáveis bioquímicas com a possibilidade da melhora clínica e consequente alta hospitalar ou com a morte.

- Santos et al. ${ }^{2}$ observaram que as concentrações de cortisol e ureia, bem como as atividades de AST e CK estavam mais elevadas no grupo de fêmeas que morreram.

- Souza et al. ${ }^{49}$ constataram elevações nas concentrações de biomarcadores sanguíneos em cabras com TP, principalmente Troponina I (cTnI), indicador relacionado a patogênese da doença envolvendo lesão cardíaca, de tal forma a recomendar seu uso para o prognóstico já que cabras com TP apresentaram concentrações de cTnI de $0,43 \mathrm{ng} / \mathrm{mL}$ enquanto as sadias apresentaram concentrações de cTnI de $0,06 \mathrm{ng} / \mathrm{mL}$.

- Simpson et al. ${ }^{41}$ observaram que cabras com nitrogênio ureico sanguíneo (BUN) acima dos valores considerados fisiológicos (3,57 a 7,14 mmol/L ou 10 a $20 \mathrm{mg} / \mathrm{dL}$ ) apresentavam 8,25 vezes mais chance de morrer do que as que apresentavam teores de BUN dentro ou abaixo dos valores fisiológicos; que as com teores de bicarbonato menores que $15 \mathrm{mEq} / \mathrm{L}$ tiveram mais chance de morrer que as sem esses achados e as submetidas à cesariana mais chance de morrer do que as de parto normal.

\section{TRATAMENTO}

Os tratamentos descritos para a TP têm resultados variáveis e podem ser economicamente inviáveis quando a doença atinge grande número de animais ${ }^{45}$. A letalidade é alta e apesar das maiores chances de sucesso ocorrerem quando o tratamento é instituído no início da doença, muitos animais ainda podem sucumbir $^{16}$.

O tratamento deve ser imediato e intensivo, visando, aumentar o suprimento de energia, glicose e, sempre que possível, proceder à correção de problemas secundários, como a desidratação, o desequilíbrio eletrolítico e a acidose metabólica. No início do quadro, isto é, quando há hiporexia e o animal ainda se mantém em estação; se locomove com relativa facilidade; apresenta leve a moderado grau de desidratação; os movimentos ruminais, mesmo que incompletos, estão presentes; e os fetos estão vivos, recomenda-se fazer o tratamento conservativo. Assim, o apetite e a função ruminal podem ser restabelecidos com o uso de fluido ruminal associado aos precursores de glicose, propilenoglicol e/ou glicerol.

Também devem ser corrigidos o déficit hidroeletrolítico e o desequilíbrio acidobásico, com base em exames laboratoriais, hemogasometria e mensuração do $\mathrm{pH}$ sanguíneo. Quando esse último não for possível, o déficit de bases deve ser estimando por meio do $\mathrm{pH}$ urinário, utilizando-se uma das fórmulas a seguir ${ }^{58,59}$ :

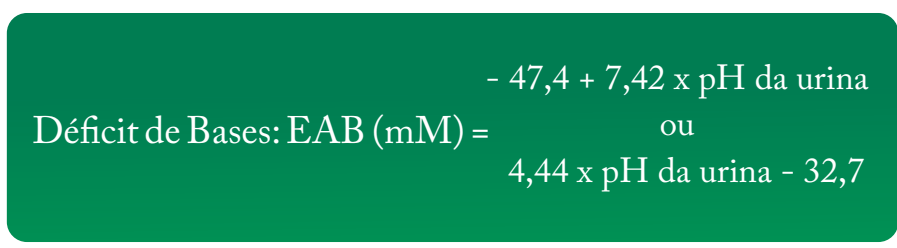

Além disso, é importante que se monitore, e ainda, nas situações de hipoglicemia e, em alguns casos até nas de normoglicemia, seja administrada solução de glicose. Nas fêmeas gestantes, quando a hiperglicemia é acentuada, e persistente, pode-se utilizar insulina (zinco protamina), na dose de 20 a 40 UI/animal a cada dois dias até a recuperação ${ }^{8}$ apesar de Simpson et al. ${ }^{41}$, em estudo retrospectivo, terem observado que animais que receberam a insulina tiveram mais chance de morrer do que os que não receberam. Certamente, mais estudos devem ser conduzidos para que tenhamos maior segurança quanto ao uso e recomendação da insulina em pequenos ruminantes com TP.

De maneira geral animais que estão hospitalizados e monitorados, podem receber glicose, em solução intravenosa, para o reestabelecimento da glicemia ${ }^{8}$ (Figura 7).

O uso oral do propilenoglicol tem sido rotineiramente usado em fêmeas com TP ou cetose na dose de $1 \mathrm{~mL} / \mathrm{kg}$ de peso vivo (B.I.D) com bons resultados ${ }^{60}$. O propilenoglicol pode ser utilizado tanto na prevenção, 
como no tratamento e sua eficácia está relacionada à elevação dos teores séricos de glicose e insulina e, diminuição dos valores de NEFA e $\mathrm{BHB}^{61}$. Andrews et al. ${ }^{15}$ ao administrarem $60 \mathrm{~mL}$ de propilenoglicol duas vezes ao dia associado a $100 \mathrm{~mL}$ de solução de dextrose a 5\% e $0,15 \mathrm{mg} / \mathrm{kg}$ de Somatotropina recombinante bovina (r-bST) obtiveram efeito benéfico no tratamento de ovelhas com TP. Em estudo realizado por Cal Pereyra et al. ${ }^{62}$ utilizando $100 \mathrm{~mL}$ de solução (B.I.D) contendo $70 \mathrm{~g}$ e $20 \mathrm{~g}$ de glicerol e propilenoglicol, respectivamente, em ovelhas com TP inaparente e hipoglicêmicas, foi observada elevação na glicemia em intervalo de doze horas.

As soluções de borogluconato de cálcio a 20\%, na dose de $1 \mathrm{~mL} / \mathrm{kg}$ de peso vivo são importantes, haja vista que baixas concentrações de cálcio sérico estão intimamente relacionadas a TP e a cetose $\mathrm{s}^{18,63,64}$.

Zamir et al. ${ }^{65}$ sugerem que o tratamento adicional com flunixin meglumine $(2,5 \mathrm{mg} / \mathrm{kg})$ pela via intramuscular, por até três dias, é capaz de reduzir a mortalidade de ovelhas com TP e melhorar sua condição clínica, provavelmente em função de seus efeitos anti-inflamatórios e aliviadores da dor, mediados por efeito inibidor sobre a formação de prostaglandina, ou ainda por outros mecanismos, ainda a serem investigados.

O uso de r-bST, administrada por injeção subcutânea $(0,15 \mathrm{mg} / \mathrm{kg}$ ou dose única da formulação de

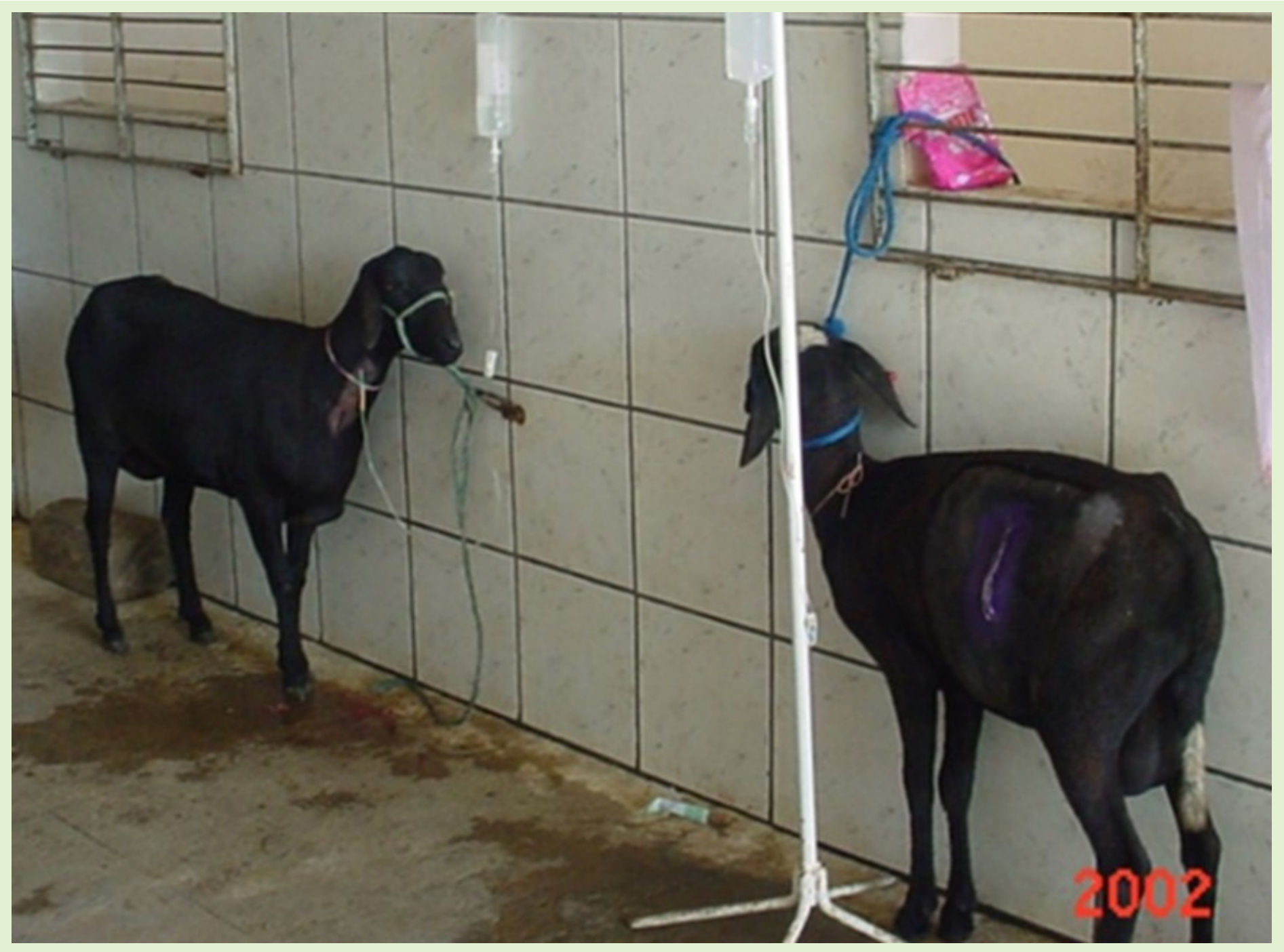

Figura 7. Ovelhas submetidas a fluidoterapia e administração de solução com glicose para recuperação da Toxemia da Prenhez (Fonte: Clínica de Bovinos de Garanhuns, UFRPE). 

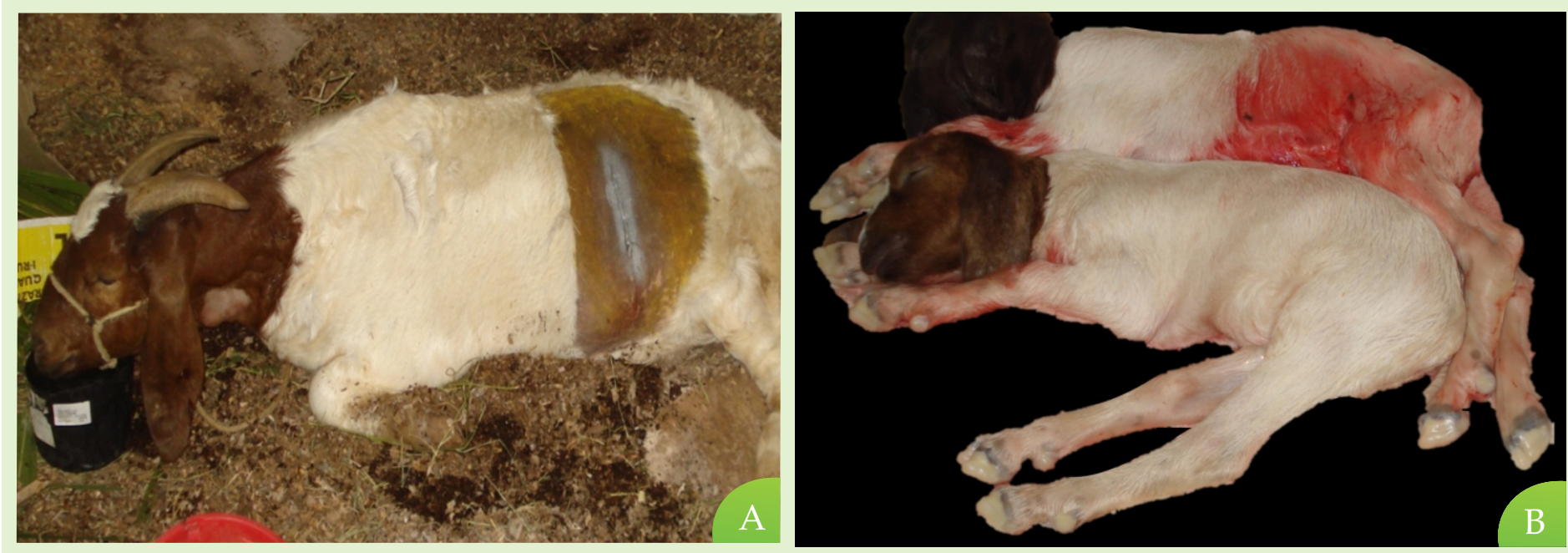

Figura 8. Cabra da raça Boer submetidas a cesariana via flanco esquerdo para o tratamento da Toxemia da Prenhez.(A) Decúbito póscirúrgico e (B) fetos gemelares retirados mortos (Fonte: Clínica de Bovinos de Garanhuns, UFRPE).

liberação lenta à $160 \mathrm{mg} / \mathrm{kg}$ ), tem alcançado taxas de sucesso iguais ou melhores do que a terapia convencional. Parece melhorar a eficiência do uso de glicose e corpos cetônicos em nível celular, reduzindo assim a mortalidade de ovelhas e fetos ${ }^{8,15,66,67}$. Feijó et al. ${ }^{67}$ administraram rbST ( $1 \mathrm{mg} / \mathrm{kg}$ ) durante o pré-parto de ovelhas e observaram que sua aplicação teve efeitos positivos no metabolismo com a redução da sobrecarga do fígado, indicado pela redução da GGT, e diminuição de BHB no período pós-parto; além de aumentar o peso dos cordeiros até a sétima semana de vida em função de maior produção de leite das fêmeas lactantes. Araújo et al. ${ }^{66}$, também sugerem que o tratamento profilático com rbST pode ser útil em ovelhas para reduzir o risco deTP.

A ocorrência do parto, principalmente em casos avançados, é um fator crucial para a recuperação das fêmeas com $\mathrm{TP}^{68}$. A cesariana nos primeiros estágios da doença, possivelmente antes do desenvolvimento do quadro clínico neurológico grave, pode ser uma opção no tratamento, pela remoção da demanda fetal por glicose, no entanto, mesmo quando realizada precocemente, as taxas de êxito são muitas vezes decepcionantes. Nos casos em que a condição clínica é grave, em que há estado pré-comatoso, o prognóstico é mau $^{8,15,69,70}$. A realização de cesariana em cabras no final de gestação com TP e hipoglicêmicas deve ser considerada, pois há indícios nessas cabras que esse achado é um bom indicador da viabilidade fetal, ao contrário do encontrado em fêmeas com hiperglicemia ${ }^{35}$. Em condições em que os fetos estão mortos e o procedimento cirúrgico seja viável diante da condição clínica da paciente, a cesariana torna-se a opção mais adequada para a obtenção dos fetos e salvar a vida da fêmea gestante (Figura 8).

\section{PREVENÇÃO}

Em função da complexidade da doença, e seus índices elevados de perdas, os esforços devem ser canalizados para a sua prevenção nos rebanhos. A atenção primária deve ser a alimentação correta nos diferentes estágios da gestação. A suplementação mais importante deve ocorrer no final de gestação, com destaque para as suas últimas seis semanas, quando os fetos estão crescendo exponencialmente, exigindo da fêmea maior requerimento de nutrientes, em especial de energia e proteína. No final da gestação a quantidade de energia oferecida varia com o número de fetos. Comparada com uma fêmea com único feto a demanda energética aumenta em 20\% e 30\% com cabras e ovelhas albergan- 
do dois e três fetos, respectivamente ${ }^{38}$. Deve-se ter maior cuidado na dieta para cabras leiteiras no início da lactação.

A atenção ao plano nutricional relacionando-o ao ECC torna-se uma importante estratégia. Um ECC ideal aos noventa dias de gestação é de 2,75 a 3,0. Se necessário, fêmeas com ECC elevado ao final do primeiro mês de gestação podem ser alimentadas de modo a perder lentamente 0,5 ponto em sua condição corporal até o terceiro mês de gestação, sem qualquer prejuízo a sua saúde. Nos últimos dois meses, em função do grande desenvolvimento fetal, em rebanhos manejados intensivamente, além do fornecimento de energia na quantidade adequada para a fêmea gestante, o concentrado deve conter no mínimo $10 \%$ de proteína. Nesse período, deve haver aumento do peso corporal em cerca de $10 \%$ para fêmeas com um feto e de $18 \%$ em gestação gemelar, mas o ECC deve permanecer em torno de 3,0 $0^{16}$. Também deve ser evitado o aumento excessivo de peso no início da gestação, sendo preferida alimentação em pastejo nessa época, reservando a suplementação com concentrado somente para o final da gestação. Todas as situações que submetam os animais ao estresse devem ser evitadas, principalmente no final de gestação ${ }^{61}$.

Uma avaliação dos animais do rebanho deve ser realizada periodicamente. Se todos os animais não puderem ser avaliados em virtude dos custos e da disponibilidade de tempo, o exame de $10 \%$ a $15 \%$ dos animais fornecerá informações valiosas. Se a determinação de corpos cetônicos no sangue, considerando valores $\mathrm{BHB}$ superiores $0,8 \mathrm{mmol} / \mathrm{L}$, não for viável, a aferição semiquantitativa na urina usando tiras reagentes pode ser utilizada, mas os resultados devem ser considerados com cautela. Animais com aumento das concentrações de corpos cetônicos no sangue ou urina devem ser separados e monitorados de perto. Se forem observados sinais precoces da doença, o tratamento deve ser imediato ${ }^{8}$.

Outra ferramenta que pode ser utilizada na profilaxia da TP é o uso do antibiótico ionóforo na dieta, neste contexto destaca-se a monensina sódica, por inibir bactérias Gram-positivas e preservar as Gram-negativas intensificando a produção de propionato, considerado o principal precursor gliconeogênico em ruminantes. Quando ofertada às ovelhas e cabras gestantes, durante e após o parto, na dose de 30 e 40 $\mathrm{mg} / \mathrm{animal} / \mathrm{dia}$, respectivamente, influencia positivamente nos indicadores metabólicos energéticos e hormonais, gerando boa perspectiva na prevenção deste transtorno metabólico ${ }^{71,72}$.

O propilenoglicol deve ser utilizado nas últimas semanas de gestação, em rebanhos em que a doença está ocorrendo, de forma preventiva, em função da sua ação imediata, até que o manejo nutricional seja ajustado.

Desse modo, estratégias de manejo devem ser adotadas e fortalecidas para diminuir a ocorrência da TP ou cetose nas propriedades, como:

- Evitar a superlotação de cabras e ovelhas em gestação e lactação em baias/aprisco, principalmente cabras que possuem uma característica de dominância muito forte e não permitem que outras se alimentem de maneira adequada;

- Determinação do número de fetos por meio de ultrassonografia e separação em lotes para o fornecimento de alimentação adequada;

- Controle do ECC por meio de correto plano nutricional desde o período de concepção até as fases de gestação e lactação;

- Controle de doenças infecciosas e parasitárias;

- Programa de melhoramento genético que forneça as matrizes características que acompanhem e suportem o ganho produtivo dessas fêmeas ao longo dos anos, seja tanto a prolificidade quanto a produção leiteira. 


\section{CONSIDERAÇÕES FINAIS}

A TP constitui-se na principal enfermidade metabólica que acomete cabras e ovelhas, gerando prejuízos imensuráveis em um sistema de produção, caracteriza-se por provocar transtornos expressivos nos indicadores do perfil metabólico, hormonal e mineral, com sua expressão (maior ou menor) nos aspectos clínicos observados, com resultados terapêuticos pífios, quando realizados numa condição clínica considerada grave, acarretando índice elevado de óbitos. Nos indivíduos em que ocorre a recuperação clínica, pode haver comprometimento produtivo. Há influência do sistema de criação e manejo alimentar que são considerados fatores importantes para a ocorrência da TP, como também suas correções são necessárias para se adotar medidas adequadas que minimizem seus impactos em índices produtivos dentro do rebanho.

\section{REFERÊNCIAS}

1. LACETERA, N. et al. Effects of subclinical pregnancy toxemia on immune responses in sheep. American Journal of Veterinary Research, v.62, n.7, p.1020$1024,2001$.

2. SANTOS, F.C.O. et al. Indicadores bioquímicos e hormonais de casos naturais de toxemia da prenhez em ovelhas. Pesquisa Veterinária Brasileira, v.31, n.11, p.974-980,2011.

3. REID, R.L. The physiopathology of undernourishment in pregnant sheep with particular reference to pregnancy toxemia.Advances in Veterinary Science, v.12, p.163-238, 1968.

4. ORTOLANI, E.L; BENESI, F.J. Ocorrência de toxemia da prenhez em cabras (Capra hircus, L) e ovelhas (Ovis aries, L) criadas no Estado de São Paulo, Brasil. Revista da Faculdade de Medicina Veterinária e Zootecnia da Universidade de São Paulo,v.26,n.2,p.229234,1989.

5. FORD, E. et al. Cortisol in pregnancy toxaemia of sheep. British Veterinary Journal, v.146, n.6, p.539-542, 1990.
6. ROOK, J.S. Pregnancy toxemia of ewes, does, and beef cows. Veterinary Clinics of North America, Food Animal and Practice,v.16, n.2, p.293-317,2000.

7. SCHLUMBOHM, C.; HARMEYER, J. Twinpregnancy increases susceptibility of ewes to hypoglycaemic stress and pregnancy toxemia. Research in Veterinary Science, v.84, n.2, p.286-299, 2008.

8. BROZOS, C. et al. Treatment and control of periparturient metabolic diseases: pregnancy toxemia, hypocalcemia, hypomagnesemia. Veterinary Clinics of North America, Food and Animal Practice, v.27, n.1, p.105-113,2011.

9. CAMPBELL, A.J. et al. Pregnancy toxemia in small ruminants: a review. Clinical Theriogenology, v.7, n.4, p.407-418,2015.

10. ORTOLANI, E.L.Toxemia da Prenhez.In: Manejo, Patologia e Clínica de Caprinos. São Paulo: Sociedade Paulista de Medicina Veterinária, 1985. p.201210 .

11. ISMAIL Z.A.B. et al. Metabolic profiles in goat does in late pregnancy with and without subclinical pregnancy toxemia. Veterinary Clinical Pathology, v.37, 
n.4,p.434-437,2008.

12. HEFNAWY, A.E. et al. Haematobiochemical profile of pregnant and experimentally pregnancy toxaemic goats. Journal of Basic Applied Chemical, v.1, n.8,p.65-69,2011.

13. FTHENAKIS et al. Health management of ewes during pregnancy. Animal Reproduction Science, v.130, n. 3-4,p.198-212,2012.

14. ORTOLANI, E.L. Doenças carenciais e metabólicas em caprinos: urolitíase e toxemia da prenhez. In: E NCONTRO NACIONAL PARA O DESENVOLVIMENTO DA ESPÉCIE CAPRINA, 3, 1994, Jaboticabal. Anais... Jaboticabal: 197 p., 1994.

15. ANDREWS, A.Pregnancy toxaemia in the ewe.In Practice,v.19,n.6, p.306-312,1997.

16. CONSTABLE P.D. et al. Pregnancy toxemia (twin lamb disease) in sheep. In: RADOSTITS, O.M. et al. Veterinary Medicine: A Textbook of the Diseases of Cattle, Horses, Sheep, Pigs and Goats. 11ªed. New York: Elsevier,2017.p.1722-1726.

17. ORTOLANI, E.L. Intoxicações Metabólicas em Ovinos: Intoxicação Cúprica. In: SILVA SOBRINHO, A.G. et al. Nutrição de Ovinos. Jaboticabal: FUNEP,1996.p.241-246.

18. SOUTO, R.J.C. et al. Achados bioquímicos, eletrolíticos e hormonais de cabras acometidas com toxemia da prenhez. Pesquisa Veterinária Brasileira, v.33, n.10,p.1174-1182,2013.

19. DUEHLMEIER, R. et al. Insulin sensitivity during late gestation in ewes affected by pregnancy toxemia and in ewes with high and low susceptibility to this disorder. Journal of Veterinary Internal Medicine, v.27,n.2,p.359-366, 2013.

20. BENNASIR, H.A.H. et al. Studies on pathogenesis and treatment of pregnancy toxaemia in sheep. European Journal of Biomedical and Pharmaceutical Sciences, v.6, n.1,p.35-48,2019.

21. XUE, Y.F. et al. Molecular mechanisms of lipid metabolism disorder in livers of ewes with pregnancy toxemia.Animal, v.13, n.5, p.992-999, 2019.

22. GONZÁLEZ, F.H.D.; SILVA S.C. Introdução à Bioquímica Clínica Veterinária. Porto Alegre: Gráfica UFRGS,2006.357p.

23. HERDT, T.H. Ruminant adaptation to negative energy balance. The Veterinary Clinics of North America: Food Animal and Practice,v.16,n.2,p.215-253, 2000.

24. OETZEL, G.R. Protein energy malnutrition in ruminants. The Veterinary Clinics of North America: Food Animal and Practice,v.4,n.2,p.317-329,1988.

25. BEITZ, D.C. Metabolismo lipídico. In: REECE, W.O. Dukes: Fisiologia dos Animais Domésticos. 11aed. Rio de Janeiro: Guanabara Koogan, 1993. p.412-429.

26. BERGMAN, E.N. Glucose metabolism in ruminants as related to hypoglycemia and ketosis. Cornell Veterinary,v.63,n.3, p.342-382, 1973.

27. BRICKNER, A. E. et al. Effects of abomasal lipid infusion on liver triglyceride accumulation and adipose lipolysis during fatty liver induction in dairy cows. Journal of Dairy Science, v.92, n.10, p.4954-4961,2009.

28. PAYNE, J.M.; PAYNE, S. The Metabolic Profile. 1aed.Oxford: Oxford University Press, 1987.179p. 
29. GOFF, J.P. Distúrbios do metabolismo dos carboidratos e lipídios, In: REECE, W.O et al. Dukes: Fisiologia dos Animais Domésticos. 13aed. Rio de Janeiro: Editora Guanabara Koogan,2017.p.522-531.

30. RÉMÉSY, C. et al. Liver metabolism of carbohydrates and lipids in ruminants: principal interaction during gestation and lactation. Reproduction, Nutrition Development,v.26, n.1B, p.205-22,1986.

31. MOALLEM, U. et al. Plasma concentrations of key metabolites and insulin in late-pregnant ewes carrying 1 to 5 fetuses. Journal of Animal Science, v.90, p.318-324,2012.

32. VAN SAUN R.J. Pregnancy toxemia in a flock of sheep. Journal of American Veterinary Medical Association v.21,n.10, p.1536-1539,2000.

33. VIJAYANAND, V. et al. Diagnostic indicators and therapeutic evaluation of clinical pregnancy toxaemia in goats. Journal of Entomology and Zoology Study, v.9, n.2,p.1110-1119,2021.

34. SOUTO R.J.C. et al. Biochemical, endocrine, and histopathological profile of liver and kidneys of sheep with pregnancy toxemia. Pesquisa Veterinária Brasileira, v.39, n.10, p.780-788, 2019.

35. Lima M.S. et al. Glycaemia as a sign of the viability of the foetuses in the last days of gestation in dairy goats with pregnancy toxaemia. Irish Veterinary Journal,v.65,n.1,p.1-6,2012.

36. ARAÚJO, C.A.S.C. Estudo comparativo do perfil metabólico e hormonal de ovelhas com gestação única, gemelar e não gestantes alimentadas com dieta de alta densidade energética.2020.212f. Tese (Doutorado em Clínica Veterinária) - Faculdade de Medicina Veterinária e Zootecnia da Universidade de São Paulo,
São Paulo, São Paulo.

37.AL-QUDAH, K.M. Oxidant and antioxidant profile of hyperketonemic ewes affected by pregnancy toxemia. Veterinary Clinical Pathology, v.40, n.1, p.6065,2011 .

38. ORTOLANI, E.L.Toxemia da prenhez em pequenos ruminantes: como reconhecê-la e evitá-la, 2007. Disponível em:

http://br.monografias.com/trabalhos901/toxemiaprenhez-ruminantes/toxemiaprenhez-ruminantes.shtml.

39. SMITH, M.C.; SHERMAN, D.M. Goat Medi-

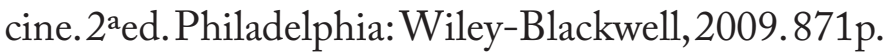
40. ZOBEL, G. et al. Ketonemia in dairy goats: effect of dry period length and effect on lying behavior.Journal of Dairy Science, v.98, n.9, p.6128-6138, 2015.

41. SIMPSON, K.M. et al. Evaluation of prognostic indicators for goats with pregnancy toxemia. Journal of American Veterinary Medical Association, v.254, n.7, p.859-867,2019.

42. JEFFREY, M.; HIGGINS, R.J. Brain lesions of naturally occurring pregnancy toxemia of sheep. Veterinary Pathology, v.29, n.4, p.301-307,1992.

43. ARAÚJO, C.A.S.C. et al. Manifestações clínicas da cetose nervosa induzida por isopropanol em ovinos. Brazilian Journal of Veterinary Research and Animal Science, v.50, n 6, p.493-496, 2013.

44. ANDRADE, I. et al. The impact of pregnancy toxemia in goats on the survival rate of newborn kids. In: 50th ANNUAL CONFERENCE OF THE AMERICAN ASSOCIATION OF BOVINE PRACTITIONERS, 50, 2017. Anais... Omaha: p. $215,2017$.

45. CAL-PEREYRA, L. et al. Ewe pregnancy tox- 
emia: review. Revista Mexicana de Ciencias Pecuarias, v.3, n.2,p.247-264,2012.

46. MACEDO, A.T.M. et al. Protein profile in ewes affected by natural pregnancy toxemia/proteinograma de ovelhas acometidas por casos naturais de toxemia da prenhez/proteinograma de ovejas afectadas por casos naturales de toxemia de la prenhez. Veterinaria e Zootecnia,v.24,n.1,p.159,2017.

47. ARAÚJO, C.A.S.C. et al. Validation of a handheld $ß$-hydroxybutyrate acid meter to identify hyperketonaemia in ewes. Peer Journal, v.8, p.e8933. 2020.

48. JACONDINO, L.R. et al. Comparação de métodos para avaliação de beta-hidroxibutirato em ovelhas. Arquivos Brasileiros de Medicina Veterinária e Zootecnia, v.71,n.3,p.857-862,2019.

49. SOUZA, L.M. et al. Changes in cardiac biomarkers in goats naturally affected by pregnancy toxemia. Research in Veterinary Science, v.130, p.73-78, 2020.

50.PICHLER, M. et al. Thresholds of whole-blood hydroxybutyrate and glucose concentrations measured with an electronic hand-held device to identify ovine hyperketonemia. Journal of Dairy Science, v.97, n.3, p.1388-1399,2014.

51. DORÉ, V.et al. Short communication: Evaluation of the accuracy of an electronic on-farm test to quantify blood $\beta$-hydroxybutyrate concentration in dairy goats. Journal of Dairy Science, v.96, n.7, p.4505-4507, 2013.

52. MORALI, S. Efermedades metabólicas en la cabra hacia el final de la gestación e início de la lactación.
Universidade Nacional Autônoma do México.s.d.8p.

53.CAMPOS, A.G.S. et al. Estudo clínicolaboratorial da toxemia da prenhez em ovelhas: análise retrospectiva. Ciência Animal Brasileira, v.11, n.3, p.623-628,2010.

54. HENZE, P. et al. Spontaneous pregnancy toaxemia (Ketosis) in sheep and the role of insulin. Journal of American Veterinary Medical Association, v.45, n.5, p.225-226, 1998.

55.SHILD, A.L.Doenças metabólicas.In:CORREA, F.R. et al. Doenças de Ruminantes e Equídeos. 3ªed. Santa Maria: Pallotti,2007.v.2,p.281-286.

56. ZAINAL ULUM, M.T. et al. Histopathological changes in the reproductive organs of does with pregnancy toxaemia and their aborted foetuses. Small Ruminant Research,v.199,p.106363,2021.

57. MARTENIUK, J. V.; HERDT, T.H. Pregnancy toxemia and ketosis of ewes and does. Veterinary Clinics of North America: Food Animal Practice, v.4, n.2, p.307315,1988 .

58. ORTOLANI, E.L.et al. O uso do pH urinário para estimar o grau de acidose metabólica em garrotes com acidose lática huminal. In: CONGRESSO DE MEDICINA VETERINÁRIA DO CONE SUL, 2, 1997.Anais...Porto Alegre, 1997.

59. MARUTA, C.A et al. The measuremente of urine $\mathrm{pH}$ to prediet the amount of buffer used in the treatment of acute rumen lactic acidosis in cattle. Ciência Rural,v.38, n.3,p.717-722,2008.

60. AFONSO, 2021. Comunicação pessoal (Clínica de Bovinos de Garanhuns, Universidade Federal Rural de Pernambuco). 
61. GONZÁLEZ, F.H.D. et al. Transtornos Metabólicos nos Animais Domésticos. 2aed. Porto Alegre: Editora da UFRGS, 2014.337p.

62. CAL-PEREYRA, L.et al. Evaluation of three therapeutic alternatives for the early treatment of ovine pregnancy toxaemia. Irish Veterinary Journal, v.68, n.5, p.1-7,2015.

63. SCHLUMBOHM, C.; HARMEYER, J. Hipocalcemia reduces endogenous glucose production in hiperketonemic sheep. Journal of Dairy Science, v.86, n.6,p.1953-1962,2003.

64. CAJUEIRO,J.F.P.Influência das concentrações de cálcio sanguíneo de cabras leiteiras no período de transição sobre o perfil energético-proteico, mineral e hormonal. 2015, 78f. Dissertação (Mestrado em Sanidade e Reprodução de Ruminantes)Universidade Federal Rural de Pernambuco, Garanhuns, Pernambuco.

65. ZAMIR, S. et al. Treatment of pregnancy toxaemia in sheep with flunixin meglumine. Veterinary Record, v.165,n.9,p.265-6,2009.

66. ARAÚJO, C.A.S.C. et al. Potential prophylactic effect of recombinant bovine somatotropin (rbST) in sheep with experimentally induced hyperketonemia. Research in Veterinary Science, v.119, p.215-220,2018.

67. FEIJÓ, J.O. et al. Administração pré-parto de somatotropina bovina recombinante (rBST) na adaptação da cetose subclínica de ovelhas e no desempenho dos cordeiros. Arquivos Brasileiros de Medicina Veterinária e Zootecnia, v.67, n.1, p.103-108, 2015.

68. WIERDA, A. et al. Effects of trampoline acetate and propylene glycol on pregnancy toxaemia in ewes.
Veterinary Record, v.116, n.11, p.284-287, 1985.

69. PUGH, D.G. Clínica de Ovinos e Caprinos. São Paulo: Roca, 2005.513p.

70. SARGISON, N.D. et al. Plasma enzymes and metabolites as potential prognostic indices of ovine pregnancy toxaemia: a preliminar study. British VeterinaryJournal,v.150, n.3, p.271-277,1994.

71. FÁTIMA, C.J.T. et al. Effects of dietary sodium monensin on the metabolic and hormonal profiles of dairy goats during the peripartum period. Ciência Animal Brasileira,v.19, n.19, p.1-13, e-51453, 2018.

72. LIMA, M.S. et al. Usefulness of clinical observations and blood chemistry values for predicting clinical outcomes in dairy goats with pregnancy toxaemia. Irish Veterinary Journal,v.69, n.1,p.1-9,2016. 